\title{
Size and Shape: Morphology's Impact on Human Speed and Mobility
}

\author{
Cara M. Wall-Scheffler ${ }^{1,2}$ \\ ${ }^{1}$ Department of Biology, Seattle Pacific University, Suite 205, 3307 3rd Avenue West, Seattle, WA 98119-1997, USA \\ ${ }^{2}$ Department of Anthropology, University of Washington Seattle, WA 98195, USA
}

Correspondence should be addressed to Cara M. Wall-Scheffler, cwallsch@spu.edu

Received 27 March 2012; Revised 23 June 2012; Accepted 11 July 2012

Academic Editor: Benjamin Campbell

Copyright (C) 2012 Cara M. Wall-Scheffler. This is an open access article distributed under the Creative Commons Attribution License, which permits unrestricted use, distribution, and reproduction in any medium, provided the original work is properly cited.

\begin{abstract}
While human sexual dimorphism is generally expected to be the result of differential reproductive strategies, it has the potential to create differences in the energetics of locomotion and the speed at which each morph travels, particularly since people have been shown to choose walking speeds around their metabolic optimum. Here, people of varying sizes walked around a track at four self-selected speeds while their metabolic rate was collected, in order to test whether the size variation within a population could significantly affect the shape of the optimal walking curve. The data show that larger people have significantly faster optimal walking speeds, higher costs at their optimal speed, and a more acute optimal walking curve (thus an increased penalty for walking at suboptimal speeds). Bigger people who also have wider bitrochanteric breadths have lower metabolic costs at their minimum than bigger people with a more narrow bitrochanteric breadth. Finally, tibia length significantly positively predicts optimal walking speed. These results suggest sex-specific walking groups typical of living human populations may be the result of energy maximizing strategies. In addition, testable hypotheses of group strategies are put forth.
\end{abstract}

\section{Introduction}

In recent years a number of key paleoanthropological finds and reconstructions have pushed into the forefront ideas of mobility strategies within and between hominin groups or species. Understanding mobility strategies is important in order to place groups within a particular adaptive environment or niche [1]. Distances traveled, time spent traveling, and group composition of a traveling party all determine the behavioral tradeoffs that provide the basis for selection pressures. For example, increasing the speed of one task, can increase the availability of time for another task (e.g., tool development [2]). Conversely, if essential foraging behavior takes up most of the day-light hours, social behaviors might suffer and group fragmentation may occur [3-5]. Studies that integrate mobility and reproductive success clearly show that the energetics of daily walking influence interbirth-intervals and offspring survivorship [69]. Studies that applied meta-analyses of ongoing selection in human populations further show a close relationship between locomotor morphology and reproductive success [10] and locomotor stress and drops in ovarian hormones [11]. Furthermore, changes in mobility have consistently been shown to influence weight loss/weight gain, and ovarian function and fecundity have consistently been shown to be particularly sensitive to changes in the metabolic balance/weight, such that an increased imbalance between energy in and energy out decreases fertility [12-17]. Such sensitivities have been shown both in energy-rich, healthy populations and also in lower body mass, less healthy populations. Thus, the speed of moving across a landscape and the energetic efficiency of mobility must be assessed together in order to understand the selection pressures involved in maintaining reproduction and accessing resources across any series of niche adaptations.

Humans and other mammals have been shown to have a curvilinear cost of transport (CoT: the metabolic cost to travel a given distance) relationship with speed during both walking and running [18-22]. This means that there is a speed at which the CoT is minimized. In reconstructions 
of mobility patterns and daily energy budgets [23, 24], assumptions are generally made that all people are traveling at their optimal speed - the speed at which the metabolic cost of walking is at the lowest [19, 25-30]. Evidence supports this general assumption that people (and other animals) adjust their speed by numerous amounts of physiological input, including energetic [27, 29, 31, 32], muscular [33, 34], and thermoregulatory [35-37], so that the speed of travel is generally near this minimum.

Given the evidence that people walk near their minimum CoT speed [19, 27-29], it remains possible that size and proportions significantly impact the speed at which walking occurs [38-40], and, as such, human populations with dimorphism may be suspected of either having different mobility strategies within the group or that part of the population accepts an energetic burden for walking at suboptimal speeds. The extent to which the dimorphism impacts actual optimal speed and the penalties for each morph to walk at sub-optimal speeds have not been measured in extant populations. Here, data on the metabolic cost of human walking are presented in order to determine the effect of within-species size variation on the CoT curves. Such data will allow us to uncover the interactions between speed, metabolic economy of mobility, and morphological variation and thus reveal the extent to which different patterns of mobility may occur within a single population.

\section{Methods}

Ten men and 10 women (age range 19-35, mean: $23.7 \pm$ 4.1) signed written informed consent forms approved by Seattle Pacific University's IRB Committee. One woman was subsequently dropped from the analysis due to a significant order effect on her CoT values; the final $\mathrm{N}$ was thus 19 individuals. Full body anthropometrics were collected, including mass, stature, lower limb length (greater trochanter to lateral malleolus), bitrochanteric breadth, biiliac breadth, and biacromial breadth. Lower limb length was further divided into thigh length (greater trochanter to the lateral joint line of the knee) and lateral shank length (midpoint to lateral malleolus). Bitrochanteric breadth and biiliac breadth were determined by pressing as tightly as possible against the relevant bony landmarks (some amount of pain was reported by participants) until the anthropometer ends could not go any further together; this was done to minimize variation due to fat or musculature deposition. To get a better sense of the length of the tibia itself, medial shank length was also measured (medial joint line to the inferior aspect of the medial malleolus of the tibia, following [41]). External measures of thigh length and medial shank length were converted into skeletal measures following [41], and crural index was calculated using these conversions.

Each participant was asked to walk around the first lane of a dirt track twice $(0.7 \mathrm{~km})$ at four different walking speeds. For each speed, a participant was given a different cue: a slow speed, a comfortable stroll, a purposeful walk, or the fastest possible walk that could be maintained. The speed was collected using a stopwatch at every half-lap. The entire protocol was repeated on three different days within a 7day period, with a different randomized order on each day; all orders were generated using http://www.random.org/ and then balanced between males and females. Breath-by-breath oxygen consumption and carbon dioxide production were monitored using an Oxycon Mobile portable ergospirometer. $\mathrm{VO}_{2}$ and $\mathrm{VCO}_{2}$ were averaged over the final minute of each walking trial, and $\mathrm{mL}$ of $\mathrm{O}_{2}$ and $\mathrm{CO}_{2}$ were used to calculate Watts following Weir [42]. Cost of transport was calculated from cost of locomotion by dividing cost of locomotion by speed. A second-order polynomial curvilinear fit was determined for each individual's speed and CoT data. Once the curvilinear fit was established, the minimum cost of transport (minCoT) was determined for each individual as well as the speed at which the minCoT occurred (the "optimal" speed). These data were analyzed in two main ways: by using $t$-tests to compare gross differences between size groups and also using predictive stepwise regressions. Models were maintained with a small number of predictors; in order to prevent any over-extrapolating, each model was tested for strong individual variation by looking at Cook's coefficients and stable beta coefficients [43].

For the $t$-tests, participants were compared both by sex and also by size groups in order to assess how much of the potential differences between the sexes were driven by size (and not some other physiological factor differing between sexes). Size groups were determined by taking the mean anthropometric measure for the group (mass, lower limb length, or bi-trochanteric breadth) and categorizing individuals by above average or below average. Independent $t$-tests were done to compare the minCoT, the speed at which the minCoT occurred (the "optimal" speed), and the $\chi^{2}$ coefficient of the curvilinear equation between the different groups. All anthropometric variables (Table 1) were put into linear regressions to assess predictive relationships on these three main variables (minCoT, optimal speed, and $\chi^{2}$ ). All statistics were done using PASW, SPSS 18.0.

\section{Results}

Participant anthropometrics are shown in Table 1. While males were statistically larger in all anthropometric measures $(P<0.03)$, the range of overlap was such that some females joined "large" size groups, and some males joined "small" size groups.

Males had faster optimal walking speeds $(10.9 \%, P=$ $0.019)$, higher minCoT $(23.4 \%, P=0.002)$, and increased curvature $(22.1 \%, P=0.276)$ (Figure 1$)$. The same patterns were generally true for "bigger" people overall. In terms of mass, larger-than-average-mass people showed faster optimal walking speeds $(13.6 \%, P=0.005)$, higher minCoT (30.2\%, $P<0.001)$, and increased curvature $(33.3 \%, P=$ $0.119)$. For people with wider bitrochanteric breadth, the significance values were similar: increased optimal walking speed $(14 \%, P=0.001)$, higher $\operatorname{minCoT}(20.6 \%, P=0.004)$, and increased curvature $(39.5 \%, P=0.067)$. The same patterns were generally true for people with longer lower limbs, though the significance values were reduced. People 
TABLe 1: Mean anthropometrics.

\begin{tabular}{lcc}
\hline \multirow{2}{*}{ Anthropometrics } & \multicolumn{2}{c}{ Mean (standard deviation) } \\
& Males $(N=10)$ & Females $(N=9)$ \\
\hline Mass $(\mathrm{kg})$ & $81.4(11.7)$ & $62.3(8.1)$ \\
Stature $(\mathrm{cm})$ & $184.5(8.0)$ & $166.7(10.6)$ \\
Lower limb length $(\mathrm{cm})$ & $87.2(7.1)$ & $79.4(7.0)$ \\
Crural index & $0.83(.05)$ & $0.78(.04)$ \\
Bitrochanteric breadth $(\mathrm{cm})$ & $32.5(1.4)$ & $30.3(1.3)$ \\
Biiliac breadth $(\mathrm{cm})$ & $28.1(1.7)$ & $26.3(2.0)$ \\
Biacromial breadth $(\mathrm{cm})$ & $37.7(3.0)$ & $34.1(2.3)$ \\
\hline
\end{tabular}

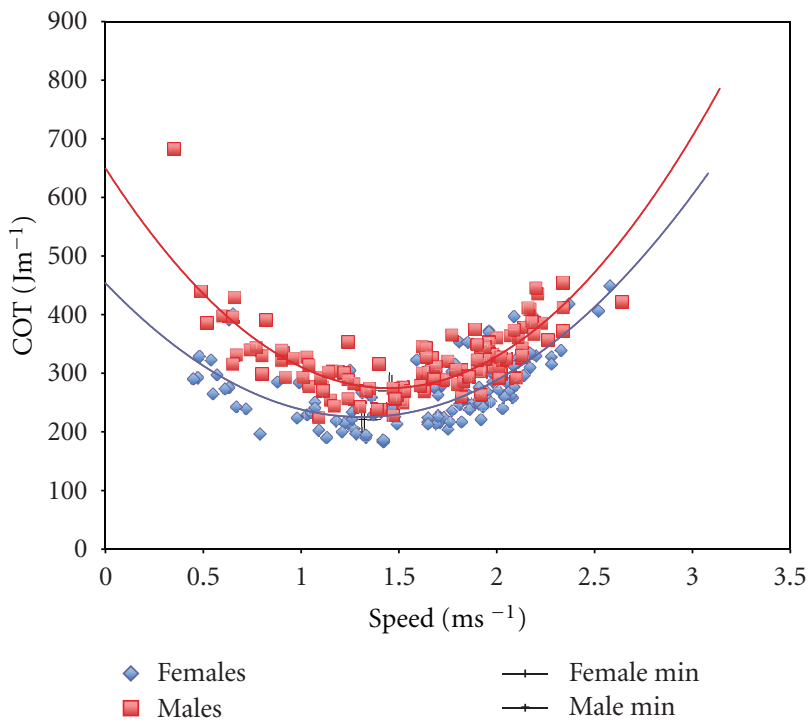

Figure 1: Data points represent CoT values for individuals at their self-selected walking speeds. Males show a faster optimal walking speed $(10.9 \%, P=0.019)$, higher minCoT $(23.4 \%, P=$ $0.002)$, and a more acute curve $(22.1 \%, P=0.276)$ than female walkers. The vertical black lines that transect the best fit lines for each sex (red and blue) mark each sex's optimal speed $\left(1.45 \mathrm{~ms}^{-1}\right.$ for males; $1.31 \mathrm{~ms}^{-1}$ for females) and $\operatorname{minCoT}\left(274.7 \mathrm{Jm}^{-1}\right.$ for males and $225.4 \mathrm{Jm}^{-1}$ for females). The female specific equation for $\operatorname{CoT}$ is $\operatorname{CoT}\left(\mathrm{Jm}^{-1}\right)=132.9 * \operatorname{Speed}^{2}\left(\mathrm{~ms}^{-1}\right)-348.6 *$ Speed $\left(\mathrm{ms}^{-1}\right)+453.8$. The male specific equation is $\operatorname{CoT}\left(\mathrm{Jm}^{-1}\right)=178.7 *$ Speed $^{2}\left(\mathrm{~ms}^{-1}\right)-517.8 *$ Speed $\left(\mathrm{ms}^{-1}\right)+649.8$.

with longer lower limbs had faster optimal walking speeds (6.5\%, $P=0.183)$, higher minCoT $(23.2 \%, P=0.001)$, and increased curvature $(11.9 \%, P=0.352)$.

In the predictive linear regressions, both mass $(P<$ $0.001)$ and bitrochanteric breadth $(P=0.036)$ significantly explained the variation in the minCoT $\left(R^{2}=0.8\right)$; neither sex nor lower limb length remained in the model. The beta coefficient for bitrochanteric breadth was negative, suggesting that for a given mass, widening the pelvis compensates for the increase in cost with increasing mass. In the regression predicting the optimal walking speed, medial calf length (tibial length) predicted the optimal walking speed the most strongly ( $P=0.006, R^{2}=0.364$ ) (optimal speed $\left(\mathrm{ms}^{-1}\right)=0.00205 *$ tibia length $\left.(\mathrm{mm})+0.5811\right)$; sex, mass, and all other anthropometrics, including crural index, were removed from the model. If either mass or bitrochanteric breadth was forced into the model with medial calf length, none reached significance. Curvature is most significantly predicted by bitrochanteric breadth alone $\left(P=0.025, R^{2}=\right.$ 0.262 ). When either mass or medial calf length was forced into the model, neither remained significant. While all three of these key variables (mass, bitrochanteric breadth, and tibial length) are correlated with each other $(P=0.001$, $R=0.7$ ), each seems to explain a slightly different piece of the variation of the CoT curves. The models with their beta coefficients are summarized in Table 2.

\section{Discussion}

4.1. Morphological Findings. As expected, body size shows a strong relationship with cost of transport (CoT) curves, and larger people have significantly faster optimal walking speeds; however, this ability to walk at faster speeds is offset by increased curvature around these faster speeds $(\sim 30 \%$ more acute). This means that the energetic penalty to walk at sub-optimal speeds is much increased in larger people-who are already paying absolutely larger costs to walk ( $\sim 20 \%$ increase in cost). A possible means of offsetting some of this increase in cost may be a wider bitrochanteric breadth $[44,45]$. A growing number of studies looking across energetics, biomechanics, and muscle activity are showing the importance of a relatively broad pelvic width during burdened locomotion particularly [44, 46-48], with a few also investigating unburdened locomotion (e.g., $[49,50]$ ). Benefits generally involve the lower center of mass that comes with a relatively broad pelvis and decreased mediolateral excursion [51]. The lower center of mass results from having more dense tissue (bone and musculature) lower in the body; this is generally a large part of the explanation for why human females have lower centers of mass (for a given mass) than males. Increased lateral stability (decreased excursion) itself has been shown to reduce energetic expenditure [49], particularly when carrying $[44,46]$.

Much of the work on stability has been accomplished within a energetic framework focused on investigating the small collisions that occur each time the foot "collides" with the ground. This model [52] is based on a passive dynamic model of walking in which, due to passive pendular exchanges of energy, much of the energetic cost for the system/organism relates to replacing energy lost in step-tostep collisions of the foot with the ground. Within such "collisional" models of the metabolic cost of walking, the focus is on lost energy as the foot hits the ground, and the energy supplied at toe off needs to restore this lost energy [52]. When the initial collision and subsequent toe off are closer to equal in magnitude and of short duration, the part of the cost of walking that relates to the cost of step transitions can be reduced [52]. Excursion of the center of mass $(\mathrm{CoM})$ increases both collisional costs and the amount of time on one limb, thus increasing the cost of recovering from the collision as well as the time when one limb must perform work against gravity [52]; reducing such excursion can reduce metabolic costs. Increased muscular contractions 
TAble 2: Predictive relationships (standardized $\beta$-coefficients) based on linear regression models that explained the most variation of the three key dependent variables. Other measured anthropometrics were not significant predictors of variation in the optimal walking curves. Significance is to the $P=0.05$.

\begin{tabular}{lccc}
\hline $\begin{array}{l}\text { Anthropometric } \\
\text { measure }\end{array}$ & MinCoT & Optimal speed & Curvature $\left(\chi^{2}\right)$ \\
\hline $\begin{array}{l}\text { Mass (kg) } \\
\begin{array}{l}\text { Bitrochanteric } \\
\text { Breadth (cm) }\end{array}\end{array}$ & -0.530 & N.S. & N.S. \\
$\begin{array}{l}\text { Tibiae length } \\
(\mathrm{cm})\end{array}$ & N.S. & 0.603 & 0.512 \\
Model $R^{2}$ & 0.800 & 0.364 & N.S. \\
SEE & 0.004 & 0.106 & 0.262 \\
\hline
\end{tabular}

of hip abductors and extensors-shown to be positively correlated with pelvic width [50]—-may speed up these collisions and thus be energetically favorable by reducing collisional costs at each step [53]. Specifically, the authors of [52] suggest that, during collision and rebound of the stance leg, positive work performed by pelvic muscles (hip flexors in particular) may accelerate the inverted pendulum motion, contributing to the forward movement of the center of mass. The energy of the center of mass motion could then be stored by ankle muscles and the Achilles tendon to aid in powering toe pushoff [52]. In other words, this work of the pelvic muscles accelerates the forward motion of the body and minimizes step-to-step transitional costs. Thus, under this model [52], appropriately timed action of hip and ankle muscles may reduce collisional losses and the need for force production to redirect the body upwards. This moderating effect can lead to less metabolic energy use overall. Furthermore, these actions, when combined with storage (e.g., in the Achilles), may influence fatigue avoidance [52] and thus may influence factors relating to speed choice (e.g., thermoregulatory $[36,54])$. Reducing CoM excursion, step-to-step collisional costs, and fatigue are three key ways a broader pelvis may reduce overall metabolic costs during walking.

Since the locomotor system involves a complicated physiological system, understanding the interactions between energy exchange at the limbs $[55,56]$, the distribution of mass across the limbs [57-59], and the importance of soft tissue (e.g., connective tissue and viscera) to accomplish positive work and allay collisional forces [60] have all been leading to a new appreciation of the role of the pelvis in allowing energetic economy. Establishing the interactions between bitrochanteric breadth, biomechanics, and energetics of walking all in the same sample should be of great interest in future work.

The role of tibia length in particular in driving speed, and thus exploitation of resources, may initially seem surprising, particularly given the focus throughout the literature on total lower limb length or even crural index. Lower limb length and crural index do have some explanatory power predicting optimal walking speed, when they are both included in a model; however, the two of them together explain about the same amount of variation $(<40 \%)$ with less significant $P$ values $(P=0.05)$ than tibia length alone $(P=0.003)$ which would explain how they (lower limb length and crural index) continually get knocked out of the model by tibia length. While only one other study has carefully looked at optimal walking speed and anthropometrics [61], and this study also found tibia length of great importance, there are few other studies that have combined morphological diversity and optimal walking speed in the same study; however, it seems likely there are numerous reasons for tibia length to have a crucial influence on the optimal walking speed. For example, the importance of distal segment length, in particular, in heat dissipation $[62,63]$ and the importance of heat dissipation for energy expenditure (due to preventing the cardiovascular system in particular from overworking to maintain consistent core and limb temperatures) $[64,65]$ may allow individuals with longer tibiae a higher optimal speed because they are more efficient at losing heat at those higher speeds, so their cost is reduced. Additionally, it seems to be well evidenced that taller individuals, with longer total limb lengths, will have "proportionately longer distal limb elements" [66] and thus some of the earlier findings purporting the importance of total limb length may actually be driven by the variance of tibia length. Finally, in studies that compare the contributions of each segment on stride length (a key variable in the CoT), the length of the distal segment in particular explains most of the variation [67], again suggesting it is tibia length that may drive some of the relationships between cost and lower limb length.

4.2. Individuals Walking Together. A series of recent fossil discoveries have shown the diversity of multiperson walking groups [68-70] and emphasized the likelihood that all individuals within groups were traveling at the same speed, despite being of different sizes. Such suggestions in light of the current study imply that some individuals are incurring an increased energetic burden for traveling at a speed other than their optimal speed. There are in fact a series of options for populations traveling together based on these findings: either small-bodied (often female) individuals travel faster than their optimal speed, large-bodied (often male) individuals travel more slowly, or individuals travel in size-specific groups. The Tanzanian footprints have only some evidence for larger individuals walking with smaller individuals and may represent primarily a mix of women and/or juveniles walking together [68]. Because females represent the energetic bottleneck for reproduction, and female fertility is sensitive to even minimal energetic perturbations $[13,14,71]$, it is unlikely that females would bear the energetic burden of increasing their walking speed. Pregnant and lactating females are particularly vulnerable to energetic strain and are not likely to increase their speed; pregnant women show steep CoT curves as well as slower optimal and preferred speeds than when they are not pregnant $[72,73]$.

The ethnographic literature is varied on how it deals with daily movement distances of specific populations, giving time spent traveling as well as rough approximations of 
TABLE 3: Lower limb bone measures $c_{v}$.

\begin{tabular}{|c|c|c|c|c|c|c|c|c|}
\hline \multirow{3}{*}{ Area } & \multirow{3}{*}{ Population } & \multirow{3}{*}{$\begin{array}{c}\text { Male } \\
\text { Femur } \\
c_{v}\end{array}$} & \multirow{3}{*}{$\begin{array}{c}\text { Female } \\
\text { Femur } \\
c_{v}\end{array}$} & \multirow{3}{*}{$\begin{array}{c}\text { Male } \\
\text { Tibia } \\
c_{v} \\
\end{array}$} & \multirow{3}{*}{$\begin{array}{c}\text { Female } \\
\text { Tibia } \\
c_{v} \\
\end{array}$} & \multirow{3}{*}{$\begin{array}{c}\text { Male } \\
\text { Crural } \\
c_{v} \\
\end{array}$} & \multirow{3}{*}{$\begin{array}{c}\text { Female } \\
\text { Crural } \\
c_{v} \\
\end{array}$} & \multirow{3}{*}{ Source } \\
\hline & & & & & & & & \\
\hline & & & & & & & & \\
\hline \multirow{9}{*}{ Africa } & East Africa & 0.0625 & 0.0690 & 0.0700 & 0.0673 & & & {$[92]$} \\
\hline & Egypt & 0.0435 & 0.0485 & 0.0497 & 0.0490 & & & {$[92]$} \\
\hline & Egypt Naqada & 0.0537 & 0.0486 & 0.0559 & 0.0496 & 0.0357 & 0.0219 & {$[93]$} \\
\hline & $\begin{array}{l}\text { Later Stone Age } \\
\text { Southern Cape }\end{array}$ & 0.0503 & 0.0716 & & & 0.0259 & 0.0250 & {$[94]$} \\
\hline & Nubia & 0.0465 & 0.0392 & 0.0617 & 0.0383 & & & {$[92]$} \\
\hline & Pygmy & 0.0477 & 0.0528 & 0.0635 & 0.0480 & & & {$[92]$} \\
\hline & San & 0.0554 & 0.0498 & 0.0640 & 0.0545 & & & {$[92]$} \\
\hline & Sudan & 0.0714 & 0.0516 & 0.0782 & 0.0676 & & & {$[92]$} \\
\hline & West Africa & 0.0230 & 0.0853 & 0.0402 & 0.1105 & & & {$[92]$} \\
\hline \multirow{14}{*}{ Europe } & Arene Candide & 0.0394 & & 0.0331 & & & & {$[95]$} \\
\hline & Anglo-Saxon & 0.0532 & 0.0526 & 0.0623 & 0.0552 & & & {$[92]$} \\
\hline & Bohemia & 0.0447 & 0.0576 & 0.0544 & 0.0659 & & & {$[92]$} \\
\hline & Bosnia & 0.0508 & 0.0503 & 0.0578 & 0.0568 & & & {$[92]$} \\
\hline & England & 0.0560 & 0.0456 & 0.0681 & 0.0464 & & & {$[92]$} \\
\hline & France & 0.0454 & 0.0462 & 0.0582 & 0.0584 & & & {$[92]$} \\
\hline & Germany & 0.0525 & 0.0464 & 0.0570 & 0.0436 & & & {$[92]$} \\
\hline & Norse & 0.0691 & 0.0528 & 0.0365 & 0.0589 & & & {$[92]$} \\
\hline & Oleni Ostrov & 0.0378 & 0.0400 & 0.0490 & 0.0146 & & & {$[95]$} \\
\hline & Skateholm & 0.0411 & 0.0390 & 0.0494 & 0.0418 & & & {$[95]$} \\
\hline & Ukrainian Mesolithic & 0.0390 & 0.0437 & 0.0495 & 0.0262 & & & {$[95]$} \\
\hline & Ukrainian Neolithic & 0.0448 & 0.0304 & 0.0608 & 0.0406 & & & {$[95]$} \\
\hline & Vedbaek & 0.0516 & 0.0351 & & 0.0600 & & & {$[95]$} \\
\hline & Vlasac & 0.0497 & 0.0384 & 0.0755 & 0.0196 & & & {$[95]$} \\
\hline \multirow{3}{*}{ Japan } & Ainu & 0.0514 & 0.0409 & 0.0475 & 0.0427 & & & {$[96]$} \\
\hline & Jomon & 0.0449 & 0.0380 & 0.0511 & 0.0465 & & & {$[96]$} \\
\hline & Kanto & 0.0514 & 0.0499 & 0.0576 & 0.0543 & & & {$[96]$} \\
\hline Australasia & Maori & 0.0413 & 0.0379 & & & & & {$[97]$} \\
\hline \multirow{4}{*}{ North America } & Eskimo & 0.0514 & 0.0511 & & & 0.0337 & 0.0301 & {$[98]$} \\
\hline & Indian & 0.0484 & 0.0491 & & & 0.0278 & 0.0256 & {$[98]$} \\
\hline & Kwakiutl & 0.0668 & 0.0183 & 0.0668 & 0.0406 & 0.0198 & 0.0268 & [99] \\
\hline & Salish & 0.0648 & 0.0440 & 0.0577 & 0.0279 & 0.0222 & 0.0247 & [99] \\
\hline South America & Tierra del Fuego & 0.0370 & 0.0000 & 0.0455 & 0.0259 & 0.0278 & 0.0259 & [100] \\
\hline
\end{tabular}

daily travel distances, sometimes by season and sometimes in annual averages. Suffice it to say, one can approximate the distances as between 6 and $17 \mathrm{~km}$, with a mean around $15 \mathrm{~km}$ [74]. Given the data presented here, this means that males would travel this distance in about 2.87 hours. Females would travel this distance in 3.18 hours, presuming they were walking at their unloaded optimal speed. Women walking unloaded may not be likely given that most ethnographic reports of women are that they are generally carrying children, food, and household items $[25,30,75]$ and thus may be walking around their loaded optimum, which is significantly slower [72]. If males chose to slow down and walk at the female unloaded optimum, it would cost them $52 \mathrm{~kJ}$ more to travel this distance. Walking with females at their preferred loaded speeds (consistent ethnographic reports of $0.9 \mathrm{~ms}^{-1}$ ) would increase males' cost $807 \mathrm{~kJ}$ which is nearly $10 \%$ of their DEE [76]. This increase is likely due to the steepness of the male CoT curve which shows dramatically higher costs at slower walking speeds (Figure 1). It is possible that the energetic constraints around walking speeds help explain widespread ethnographic observations of single sex travel parties, who often travel different distances 
[74, 77-80]. In fact, new work on the Hadza suggests that sex differences in spatial awareness stem specifically from the fact that males travel alone and females travel together [81]. Ethnographic data also suggests that males and females do spend different amounts of time foraging, with females spending less time in terms of a daily average [82]; this makes sense given the energetic findings presented here.

4.3. Speed as a Selection Pressure. For example, if speed is particularly related to size, and females tend to walk together whereas males tend to walk singly or in pairs [74], then females may show less size variation than males, particularly in those measures that relate specifically to the speed of locomotion, such as tibia length. This hypothesis can be provisionally examined by looking at available reports of size variables among human populations. By focusing on those studies that report standard deviation measures of skeletal material (Table 3), and comparing male and female coefficients of variation $\left(c_{v}\right)$, it can be determined that females do have smaller $c_{v}$ than males in terms of femur length, tibia length, and crural index, though this reaches significance only for tibia length $(t$-test, $P=0.048$ for tibia length; $P>0.2$ for femur length and crural index). It could be argued that this relationship is simply a correlation of women's general buffering from times of energetic stress [83], and, as such, females are going to generally have reduced variability across size variables; however, studies of living populations, that include measures of stature and sitting height (See Table S1 Supplementary Material available online at doi:10.1155/2012/340493), do not show such significant differences, nor do females always have reduced variability. It thus seems that it is particularly in variables of importance to locomotion that females show such reduced variation, suggesting a selection pressure on females to travel together while reducing the energetic penalties for walking at sub-optimal speeds. This would allow females to reduce the potential energetic penalty for walking with people of a different size.

A mobility argument for explaining limb proportions must be balanced with the understanding that adult limb proportions are the outcome of both genetic and epigenetic factors. For example, nutritional dearth during gestation and/or development can result in decreased [84] or increased [85] relative lower limb length. Climatic factors have also consistently shown strong influences on limb proportions [86, 87]; however, genetics powerfully impact lower limb proportions [88], even considering short-term environmental factors such as nutrition and hypoxia [89]. As such, adult limb length can be viewed as the outcome of a range of key environmental interactions [90] but heavily impacted by the cumulative effects of selection, including selection for mobility [74].

This study thus implies that size variation leads to variation in the optimal speed of travel by individuals. Speed differences can be implicated in mobility strategy differences, and suggests that population movement may vary by each individual's size or risk substantial cost increases. If subsistence needs do not ensure division of mobility strategies, then morphological components may allow an increase in energetic flexibility (e.g., increased pelvis width). Finally, any size variation that reduces speed of travel (regardless of the cause of the variation-climate, nutrition, mobility, or otherwise) comes with a cost of either reduced foraging ability or reduced time available for other factors such as sociality [3], tool development [2, 91], or other innovations.

\section{Acknowledgments}

This research was funded by the Murdock Charitable Trust, Grant 2006194:JVA: 11/16/2006. The funders had no role in study design, data collection and analysis, decision to publish, or preparation of the paper. Data collection was augmented by the support of J. Gonzalez, M. Gonzalez, J. Pike, and K. Kjosness. S. O'Hara, K. Steudel, and M. J. Myers offered numerous helpful comments which significantly improved the paper. The comments of three anonymous reviewers were also appreciated. R. Graves and C. Ruff provided additional information pertaining to their studies for which the author is grateful. The author is further appreciative to the participants who graciously donated their time and energy to this research.

\section{References}

[1] R. A. Foley, "Evolutionary ecology of fossil hominids," in Evolutionary Ecology and Human Behavior, E. A. Smith and B. Winterhalder, Eds., pp. 131-164, Aldine de Gruyter, New York, NY, USA, 1992.

[2] R. Torrence, "Time budgeting and hunter-gatherer technology," in Hunter-Gatherer Economy in Prehistory, G. Bailey, Ed., pp. 11-22, Cambridge University Press, Cambridge, UK, 1983.

[3] R. I. M. Dunbar, "Time: a hidden constraint on the behavioural ecology of baboons," Behavioral Ecology and Sociobiology, vol. 31, no. 1, pp. 35-49, 1992.

[4] R. A. Hill, L. Barrett, D. Gaynor et al., "Day length, latitude and behavioural (in)flexibility in baboons (Papio cynocephalus ursinus)," Behavioral Ecology and Sociobiology, vol. 53, no. 5, pp. 278-286, 2003.

[5] K. A. Pollard and D. T. Blumstein, "Time allocation and the evolution of group size," Animal Behaviour, vol. 76, no. 5, pp. 1683-1699, 2008.

[6] N. B. Jones, "Bushman birth spacing: a test for optimal interbirth intervals," Ethology and Sociobiology, vol. 7, no. 2, pp. 91-105, 1986.

[7] N. Blurton Jones, "Bushman birth spacing: direct tests of some simple predictions," Ethology and Sociobiology, vol. 8, no. 3, pp. 183-203, 1987.

[8] N. Blurton Jones, K. Hawkes, and J. F. O'Connell, "Modelling and measuring costs of children in two foraging societies," in The Behavioural Ecology of Humans and Other Mammals, V. Standen and R. A. Foley, Eds., pp. 367-390, Blackwell Scientific Publications, Oxford, UK, 1989.

[9] M. A. Gibson and R. Mace, "An energy-saving development initiative increases birth rate and childhood malnutrition in rural Ethiopia," PLoS Medicine, vol. 3, no. 4, pp. 476-484, 2006. 
[10] S. C. Stearns, S. G. Byars, D. R. Govindaraju, and D. Ewbank, "Measuring selection in contemporary human populations," Nature Reviews Genetics, vol. 11, no. 9, pp. 611-622, 2010.

[11] M. J. Devlin, "Estrogen, exercise, and the skeleton," Evolutionary Anthropology, vol. 20, no. 2, pp. 54-61, 2011.

[12] A. Emaus, M. B. Veierød, A. S. Furberg et al., "Physical activity, heart rate, metabolic profile, and estradiol in premenopausal women," Medicine and Science in Sports and Exercise, vol. 40, no. 6, pp. 1022-1030, 2008.

[13] P. T. Ellison, "Energetics and reproductive effort," American Journal of Human Biology, vol. 15, no. 3, pp. 342-351, 2003.

[14] P. T. Ellison, "Energetics, reproductive ecology and human evolution," PaleoAnthropology, pp. 172-200, 2008.

[15] A. Ziomkiewicz, P. T. Ellison, S. F. Lipson, I. Thune, and G. Jasienska, "Body fat, energy balance and estradiol levels: a study based on hormonal profiles from complete menstrual cycles," Human Reproduction, vol. 23, no. 11, pp. 2555-2563, 2008.

[16] G. Jasienska and P. Ellison, "Energetic factors and seasonal changes in ovarian function in women from rural Poland," American Journal of Human Biology, vol. 16, no. 5, pp. 563580, 2004.

[17] I. L. Pike, "Maternal stress and fetal responses: evolutionary perspectives on preterm delivery," American Journal of Human Biology, vol. 17, no. 1, pp. 55-65, 2005.

[18] S. J. Wickler, D. F. Hoyt, E. A. Cogger, and M. H. Hirschbein, "Preferred, speed and cost of transport: the effect of incline," Journal of Experimental Biology, vol. 203, no. 14, pp. 21952200, 2000.

[19] H. J. Ralston, "Energy-speed relation and optimal speed during level walking," Internationale Zeitschrift für Angewandte Physiologie Einschliesslich Arbeitsphysiologie, vol. 17, no. 4, pp. 277-283, 1958.

[20] K. L. Steudel-Numbers and C. M. Wall-Scheffler, "Optimal running speed and the evolution of hominin hunting strategies," Journal of Human Evolution, vol. 56, no. 4, pp. 355-360, 2009.

[21] D. F. Hoyt and C. R. Taylor, "Gait and the energetics of locomotion in horses," Nature, vol. 292, no. 5820, pp. 239240, 1981.

[22] V. A. Langman, M. F. Rowe, T. J. Roberts, N. V. Langman, and C. R. Taylor, "Minimum cost of transport in Asian elephants: do we really need a bigger elephant?" The Journal of Experimental Biology, vol. 215, pp. 1509-1514, 2012.

[23] W. R. Leonard and M. L. Robertson, "Comparative primate energetics and hominid evolution," American Journal of Physical Anthropology, vol. 102, pp. 265-281, 1997.

[24] K. L. Steudel-Numbers and M. J. Tilkens, "The effect of lower limb length on the energetic cost of locomotion: implications for fossil hominins," Journal of Human Evolution, vol. 47, no. 1-2, pp. 95-109, 2004.

[25] G. R. Bentley, "Hunter-gatherer energetics and fertility: a reassessment of the!Kung San," Human Ecology, vol. 13, pp. 79-109, 1985.

[26] P. A. Kramer and I. Sarton-Miller, "The energetics of human walking: is Froude number $(\mathrm{Fr})$ useful for metabolic comparisons?" Gait and Posture, vol. 27, no. 2, pp. 209-215, 2008.

[27] R. C. Browning, E. A. Baker, J. A. Herron, and R. Kram, "Effects of obesity and sex on the energetic cost and preferred speed of walking," Journal of Applied Physiology, vol. 100, no. 2, pp. 390-398, 2006.

[28] R. C. Browning and R. Kram, "Energetic cost and preferred speed of walking in obese vs. normal weight women," Obesity Research, vol. 13, no. 5, pp. 891-899, 2005.
[29] N. Peyrot, D. Thivel, L. Isacco, J. B. Morin, A. Belli et al., "Why does walking economy improve after weight loss in obese adolescents?" Medicine and Science in Sports and Exercise, vol. 44, pp. 659-665, 2012.

[30] F. W. Marlowe, "Central place provisioning: the Hadza as an example," in Feeding Ecology in Apes and Other Primates, G. Hohmann, M. Robbins, and C. Boesch, Eds., pp. 359-377, Cambridge University Press, Cambridge, UK, 2006.

[31] S. J. Wickler, D. F. Hoyt, E. A. Cogger, and K. M. Hall, "Effect of load on preferred speed and cost of transport," Journal of Applied Physiology, vol. 90, no. 4, pp. 1548-1551, 2001.

[32] C. M. Wall-Scheffler and M. J. Myers, "Reproductive costs for everyone: how female loads impact human mobility strategies," Journal of Human Evolution. In press.

[33] M. Ackermann and A. J. Van Den Bogert, "Predictive simulation of gait in rehabilitation," in Proceedings of the 32nd Annual International Conference of the IEEE Engineering in Medicine and Biology Society (EMBC '10), pp. 5444-5447, September 2010.

[34] R. H. Miller, B. R. Umberger, J. Hamill, and G. E. Caldwell, "Evaluation of the minimum energy hypothesis and other potential optimality criteria for human running," Proceedings of the Royal Society B, vol. 279, no. 1733, pp. 1498-1505, 2012.

[35] N. G. Blurton Jones and R. M. Sibly, "Testing adaptiveness of culturally determined behaviour: do Bushman women maximize their reproductive success by spacing births widely and foraging seldom?" in Human Behaviour and Adaptation, V. Reynolds and N. G. Blurton Jones, Eds., pp. 135-157, Taylor and Francis, London, UK, 1978.

[36] S. J. Ulijaszek, "Potential seasonal ecological challenge of heat strain among Australian Aboriginal people practicing traditional subsistence methods: a computer simulation," American Journal of Physical Anthropology, vol. 116, no. 3, pp. 236-245, 2001.

[37] C. M. Wall-Scheffler and M. J. Myers, "Is female morphology selected for ecomony and male morphology selected for efficiency? Evidence from studies on humans," American Journal of Physical Anthropology, vol. 54, p. 296, 2012.

[38] P. A. Kramer and A. D. Sylvester, "Bipedal form and locomotor function: understanding the affects of size and shape on velocity and energetics," PaleoAnthropology, pp. 238-251, 2009.

[39] P. A. Kramer and G. G. Eck, "Locomotor energetics and leg length in hominid bipedality," Journal of Human Evolution, vol. 38, no. 5, pp. 651-666, 2000.

[40] W. R. Leonard and M. L. Robertson, "Energetic efficiency of human bipedality," American Journal of Physical Anthropology, vol. 97, no. 3, pp. 335-338, 1995.

[41] A. M. W. Porter, Physique and the Skeleton [Ph.D. dissertation], University of London, London, UK, 1996.

[42] J. B. Weir, "New methods for calculating metabolic rate with special reference to protein metabolism," The Journal of Physiology, vol. 109, no. 1-2, pp. 1-9, 1949.

[43] A. Field, Discovering Statistics Using SPSS, Sage, London, UK, 2009.

[44] C. M. Wall-Scheffler, K. Geiger, and K. L. Steudel-Numbers, "Infant carrying: the role of increased locomotory costs in early tool development," American Journal of Physical Anthropology, vol. 133, no. 2, pp. 841-846, 2007.

[45] Y. Rak, "Lucy's pelvic anatomy: its role in bipedal gait," Journal of Human Evolution, vol. 20, no. 4, pp. 283-290, 1991.

[46] D. A. Neumann and T. M. Cook, "Effect of load and carrying position on the electromyographic activity of the gluteus 
medius muscle during walking," Physical Therapy, vol. 65, no. 3, pp. 305-311, 1985.

[47] M. LaFiandra, R. C. Wagenaar, K. G. Holt, and J. P. Obusek, "How do load carriage and walking speed influence trunk coordination and stride parameters?" Journal of Biomechanics, vol. 36, no. 1, pp. 87-95, 2003.

[48] L. T. Gruss, C. M. Wall-Scheffler, and N. Malik, "Infant carrying in humans: interactions between morphometric and gait parameters," American Journal of Physical Anthropology, supplement 48, pp. 182-183, 2009.

[49] J. M. Donelan, D. W. Shipman, R. Kram, and A. D. Kuo, "Mechanical and metabolic requirements for active lateral stabilization in human walking," Journal of Biomechanics, vol. 37, no. 6, pp. 827-835, 2004.

[50] C. M. Wall-Scheffler, E. Chumanov, K. Steudel-Numbers, and B. Heiderscheit, "Electromyography activity across gait and incline: the impact of muscular activity on human morphology," American Journal of Physical Anthropology, vol. 143, no. 4, pp. 601-611, 2010.

[51] A. D. Kuo, "Stabilization of lateral motion in passive dynamic walking," International Journal of Robotics Research, vol. 18, no. 9, pp. 917-930, 1999.

[52] A. D. Kuo, J. M. Donelan, and A. Ruina, "Energetic consequences of walking like an inverted pendulum: step-tostep transitions," Exercise and Sport Sciences Reviews, vol. 33, no. 2, pp. 88-97, 2005.

[53] A. D. Kuo, "Choosing your steps carefully," IEEE Robotics and Automation Magazine, vol. 14, no. 2, pp. 18-29, 2007.

[54] C. M. Wall-Scheffler and M. J. Myers, "Is female morphology selected for economy and male morphology selected for efficiency? Evidence from studies on humans," American Journal of Physical Anthropology, vol. 54, p. 296, 2012.

[55] M. A. Fedak, N. C. Heglund, and C. R. Taylor, "Energetics and mechanics of terrestrial locomotion. II. Kinetic energy changes of the limbs and body as a function of speed and body size in birds and mammals," Journal of Experimental Biology, vol. 97, pp. 23-40, 1982.

[56] J. S. Gottschall and R. Kram, "Mechanical energy fluctuations during hill walking: the effects of slope on inverted pendulum exchange," Journal of Experimental Biology, vol. 209, no. 24, pp. 4895-4900, 2006.

[57] R. L. Marsh, D. J. Ellerby, J. A. Carr, H. T. Henry, and C. I. Buchanan, "Partitioning the energetics of walking and running: swinging the limbs is expensive," Science, vol. 303, no. 5654 , pp. $80-83,2004$.

[58] R. L. Marsh, D. J. Ellerby, H. T. Henry, and J. Rubenson, "The energetic costs of trunk and distal-limb loading during walking and running in guinea fowl Numida meleagris: I. Organismal metabolism and biomechanics," Journal of Experimental Biology, vol. 209, no. 11, pp. 2050-2063, 2006.

[59] M. J. Myers and K. Steudel, "Effect of limb mass and its distribution on the energetic cost of running," Journal of Experimental Biology, vol. 116, pp. 363-373, 1985.

[60] K. E. Zelik and A. D. Kuo, "Human walking isn't all hard work: evidence of soft tissue contributions to energy dissipation and return," Journal of Experimental Biology, vol. 213, no. 24, pp. 4257-4264, 2010.

[61] S. Bereket, "Effects of anthropometric parameters and stride frequency on estimation of energy cost of walking," Journal of Sports Medicine and Physical Fitness, vol. 45, no. 2, pp. 152$161,2005$.

[62] L. Irving and J. Krog, "Temperature of skin in the arctic as a regulator of heat," Journal of Applied Physiology, vol. 7, no. 4, pp. 355-364, 1955.
[63] E. Trinkaus, "Neanderthal limb proportions and cold adaptation," in Aspects of Human Evolution, C. B. Stringer, Ed., pp. 187-224, Taylor \& Francis, London, UK, 1981.

[64] J. R. Speakman and E. Król, "Maximal heat dissipation capacity and hyperthermia risk: neglected key factors in the ecology of endotherms," The Journal of Animal Ecology, vol. 79, no. 4, pp. 726-746, 2010.

[65] J. Gonzalez-Alonso, "Human thermoregulation and the cardiovascular system,” Experimental Physiology, vol. 97, no. 3, pp. 340-346, 2012.

[66] B. M. Auerbach and A. D. Sylvester, "Allometry and apparent paradoxes in human limb proportions: implications for scaling factors," American Journal of Physical Anthropology, vol. 144, no. 3, pp. 382-391, 2011.

[67] F. Leurs, Y. P. Ivanenko, A. Bengoetxea et al., "Optimal walking speed following changes in limb geometry," Journal of Experimental Biology, vol. 214, no. 13, pp. 2276-2282, 2011.

[68] A. Gibbons, "Ancient footprints tell tales of travel," Science, vol. 332, pp. 534-535, 2011.

[69] M. R. Bennett, J. W. K. Harris, B. G. Richmond et al., "Early hominin foot morphology based on 1.5-million-yearold footprints from Ileret, Kenya," Science, vol. 323, no. 5918, pp. 1197-1201, 2009.

[70] B. G. Richmond, K. G. Hatala, W. E. H. Harcourt-Smith, V. Rossi, A. Metallo et al., "Early modern human footprint assemblage from Engare Sero, Tanzania," PaleoAnthropology, vol. 2011, p. 29, 2011.

[71] L. C. Aiello and C. Key, "Energetic consequences of being a Homo erectus female," American Journal of Human Biology, vol. 14, no. 5, pp. 551-565, 2002.

[72] C. M. Wall-Scheffler and M. J. Myers, "Reproductive costs for everyone: how female frontal loads impact mobility," American Journal of Physical Anthropology, supplement 48, p. 414, 2009.

[73] J. M. Falola, P. Gouthon, F. E. Koussihouédé, B. Agossa, and J. Brisswalter, "Gait coordination in pregnancy: a study in a rural population in Africa," Science and Sports, vol. 24, no. 1, pp. 49-51, 2009.

[74] L. R. Binford, Constructing Frames of Reference: An Analytical Method for Archaeological Theory Building Using HunterGatherer and Environmental Data Sets, University of California Press, Berkeley, Calif, USA, 2001.

[75] R. Lloyd, B. Parr, S. Davies, and C. Cooke, "Subjective perceptions of load carriage on the head and back in Xhosa women," Applied Ergonomics, vol. 41, no. 4, pp. 522-529, 2010.

[76] W. R. Leonard and M. L. Robertson, "Nutritional requirements and human evolution: a bioenergetics model," American Journal of Physical Anthropology, vol. 4, pp. 179-195, 1992.

[77] K. Hawkes, J. F. O’Connell, and N. Blurton Jones, "Hardworking Hadza grandmothers," in Comparative Socioecology: The Behavioural Ecology of Humans and Other Mammals, V. Standen and R. A. Foley, Eds., pp. 341-366, Blackwell Scientific Publications, Oxford, UK, 1989.

[78] A. M. Hurtado, K. Hawkes, K. Hill, and H. Kaplan, "Female subsistence strategies among Ache hunter-gatherers of Eastern Paraguay," Human Ecology, vol. 13, no. 1, pp. 1-28, 1985.

[79] B. Scelza and R. Bliege Bird, "Group structure and female cooperative networks in Australia's western desert," Human Nature, vol. 19, no. 3, pp. 231-248, 2008.

[80] R. Layton and S. O'Hara, "Human social evolution: a comparison of hunter-gatherer and chimpanzee social organization," Proceedings of the British Academy, vol. 158, pp. 83507, 2010. 
[81] E. Cashdan, F. W. Marlowe, A. Crittenden, C. Porter, and B. M. Wood, "Sex differences in spatial cognition among Hadza foragers," Evolution and Human Behavior, vol. 33, pp. 274284, 2012.

[82] N. M. Waguespack, "The organization of male and female labor in foraging societies: implications for early paleoindian archaeology," American Anthropologist, vol. 107, no. 4, pp. 666-676, 2005.

[83] D. W. Frayer and M. H. Wolpoff, "Sexual dimorphism," Annual Review of Anthropology, vol. 14, pp. 429-473, 1985.

[84] B. Bogin and M. I. Varela-Silva, "Leg length, proportion, health and beauty: a review," Anthropologischer Anzeiger, vol. 67, no. 4, pp. 439-459, 2009.

[85] J. J. McGrath, D. Keeping, S. Saha, D. C. Chant, D. E. Lieberman, and M. J. O'Callaghan, "Seasonal fluctuations in birth weight and neonatal limb length; does prenatal vitamin D influence neonatal size and shape?" Early Human Development, vol. 81, no. 7, pp. 609-618, 2005.

[86] D. F. Roberts, Climate and Human Variability, Cummings Publishing Company, Philippines, 1978.

[87] C. B. Ruff, "Morphological adaptation to climate in modern and fossil hominids," American Journal of Physical Anthropology, vol. 95, no. 19, pp. 65-107, 1994.

[88] A. H. Schultz, "Fetal growth of man and other primates," The Quarterly Review of Biology, vol. 1, pp. 465-521, 1926.

[89] S. M. Bailey, J. Xu, J. H. Feng, X. Hu, C. Zhang, and S. Qui, "Tradeoffs between oxygen and energy in tibial growth at high altitude," American Journal of Human Biology, vol. 19, no. 5, pp. 662-668, 2007.

[90] J. T. Stock, M. O’Neill, C. B. Ruff, M. Zabecki, L. Shackelford et al., "Body size, skeletal biomechanics, mobility and habitual activity from the Late Palaeolithic to mid-Dynastic Nile Valley," in Human Bioarchaeology of the Transition to Agriculture, R. Pinhasi and J. T. Stock, Eds., pp. 347-370, Wiley-Blackwell, Oxford, UK, 2011.

[91] R. Torrence, "Retooling: towards a behavioral theory of stone tools," in Time, Energy and Stone Tools, R. Torrence, Ed., pp. 57-66, Cambridge University Press, Cambridge, UK, 1989.

[92] T. W. Holliday, Body Size and Proportions in the Late Pleistocene Western Old World and the Origins of Modern Humans, University of New Mexico, Albuquerque, Mexico, 1995.

[93] E. Warren, "An investigation on the variability of the human skeleton: with especial reference to the Naqada race discovered by Professor Flinders Petrie in his explorations in Egypt," Philosophical Transactions of the Royal Society B, vol. 189, pp. 135-227, 1897.

[94] J. Sealy and S. Pfeiffer, "Diet, body size and landscape use among Holocene people in the Southern Cape, South Africa," Current Anthropology, vol. 41, pp. 642-655, 2000.

[95] K. Jacobs, "Human postcranial variation in the Ukranian Mesolithic-Neolithic," Current Anthropology, vol. 34, pp. 311-324, 1993.

[96] W. Takigawa, "Metric comparison of limb bone characteristics between the Jomon and Hokkaido Ainu," Anthropological Science, vol. 113, pp. 43-61, 2005 (Japanese).

[97] G. Schofield, "Metric and morphological features of the femur of the New Zealand Maori," Journal of the Royal Anthropological Institute of Great Britain and Ireland, vol. 89, pp. 89-105, 1959.

[98] A. H. Schultz, "Proportions, variability, and asymmetries of the long bones of the limbs and the clavicles in man and apes," Human Biology, vol. 9, pp. 281-328, 1937.
[99] G. A. Dorsey, "The long bones of Kwakiutl and Salish Indians," American Anthropologist, vol. 10, pp. 174-182, 1897.

[100] J. G. Garson, "On the inhabitants of Tierra del Fuego," Journal of the Royal Anthropological Institute of Great Britain and Ireland, vol. 15, pp. 141-160, 1886. 


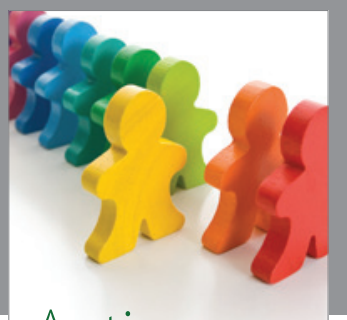

Autism

Research and Treatment
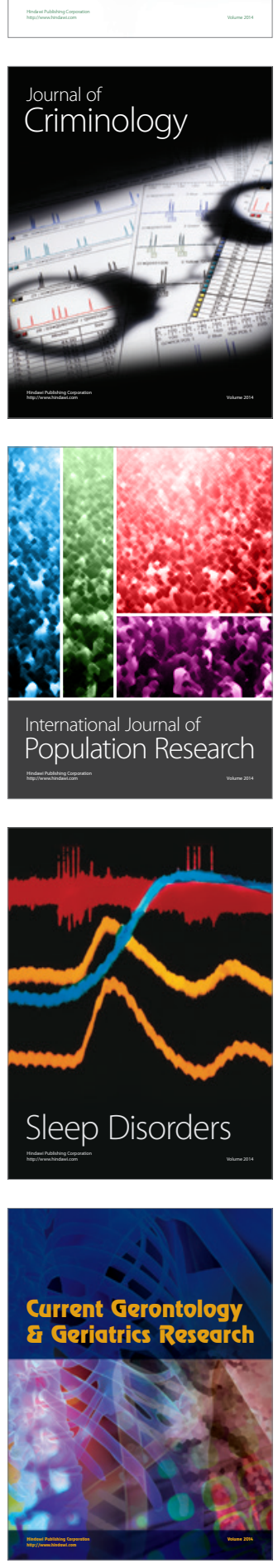
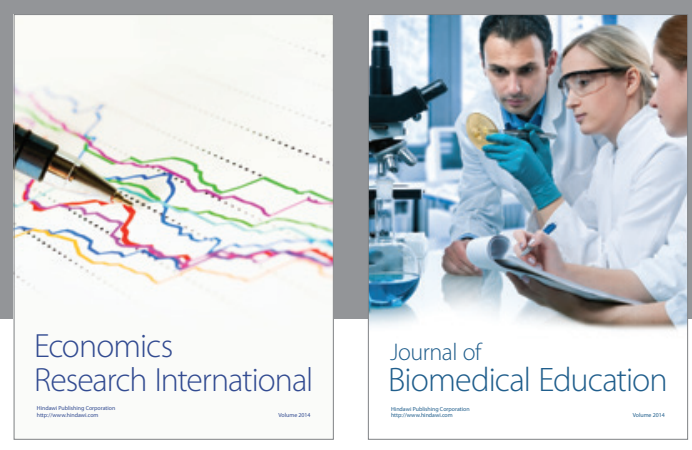

Journal of

Biomedical Education

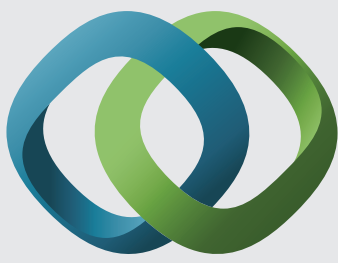

\section{Hindawi}

Submit your manuscripts at

http://www.hindawi.com
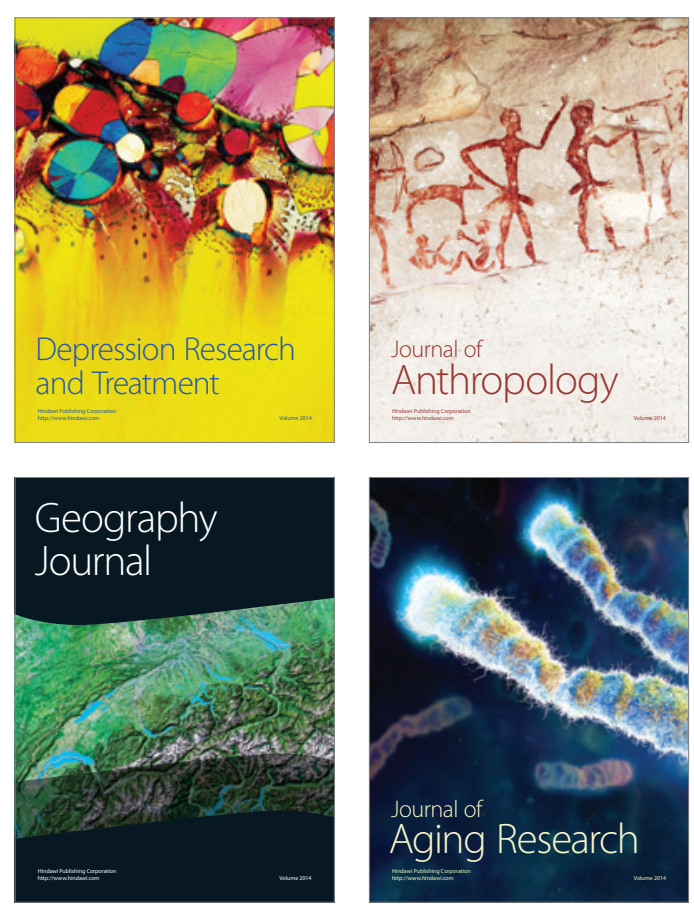

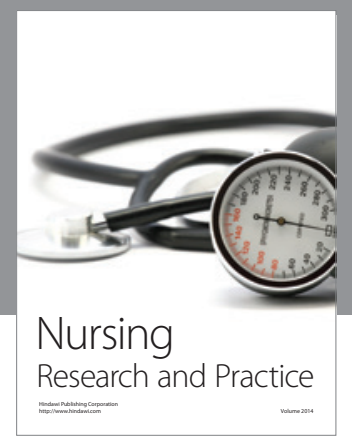

Nursing

Research and Practice

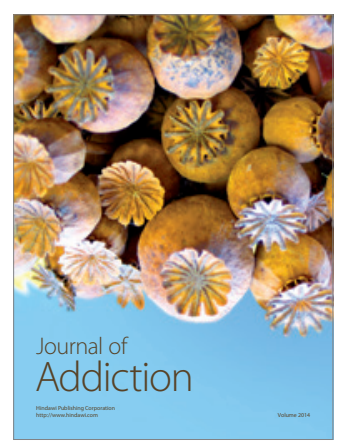

Child Development

Research

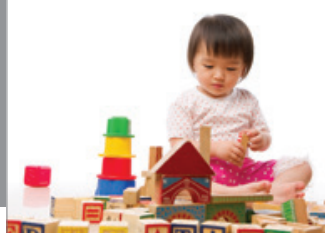

迥
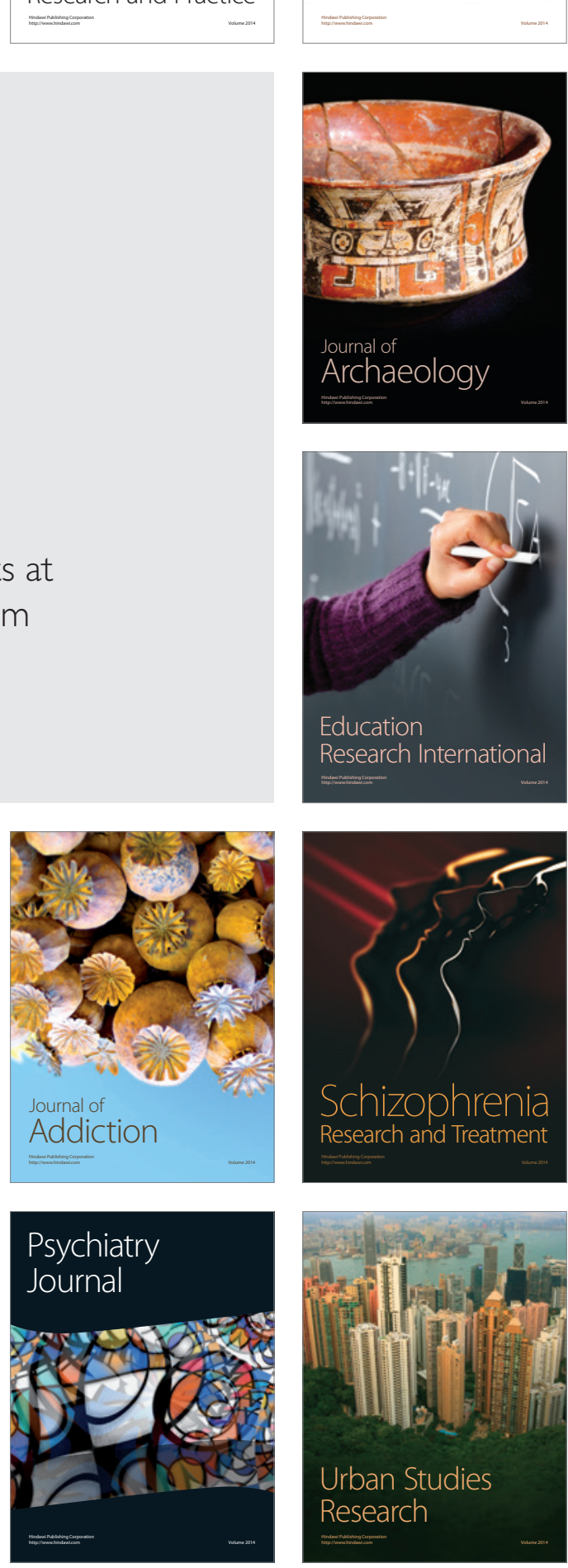